\title{
SUBARACHNOID HAEMORRHAGE IN AN ELDERLY PATIENT WITH COMORBIDITIES
}

\author{
VICENȚIU SĂCELEANU ${ }^{1}$, ALEXANDRU BABEU ${ }^{2}$, ADRIANA SĂCELEANU ${ }^{3}$ \\ 1,2 “Lucian Blaga” University of Sibiu, ${ }^{2}$ Clinical County Emergency Hospital of Sibiu
}

\begin{abstract}
Keywords: $\quad$ subdural Abstract: Subdural hemorrhage is usually caused by a traumatic injury. Other risk factors that may haemorrhage, traumatic lead to subdural hemorrhage include: hypertension, anticoagulants, elderly, alcohol abuse, vascular injury, chronic subdural abnormalities etc. Mortality range is between 50\% and 90\% depending on age, admission Glasgow hematoma, anticoagulants, hypertension Coma Scale (GCS) and anticoagulant treatment. We present a case of 74-year old patient, female, known for diabetes, high blood pressure, obesity, chronic heart failure, receiving anticoagulant treatment, bronchial asthma who develops a posttraumatic massive chronic subdural hematoma accompanied by comorbidities.
\end{abstract}

\section{INTRODUCTION}

Subdural haemorrhage is defined by a bleeding between dura mater and arachnoid, usually caused by a traumatic injury. Depending on time, it can be classified into: acute (1-3 days), subacute (4 days-2 weeks), chronic (over 2 weeks). The source of bleeding comes from bridging veins that cross the subdural space. While acute subdural haemorrhage is often caused by a traumatic injury, chronic subdural haemorrhage is associated with trauma in less than $50 \%$ cases and usually occur in elderly patients. Risk factors that may lead to subdural haemorrhage include: hypertension, anticoagulants, elderly, alcohol abuse, vascular abnormalities.(1) Receiving anticoagulation therapy is an important risk factor especially for females. Subdural hematoma may occur with or without a trauma injury in a patient receiving anticoagulation. $(2,3)$

Symptomatology may include: headache, confusion, dysphasia, hemiplegia, seizures or coma.(2)

On CT examination, the subdural haematoma appears as a hyperdense area adjacent to inner table usually associated with oedema. The most common location is supratentorial convexity and also interhemispheric, layering on tentorium and posterior fossa. The density changes on CT with time (acute hyperdense; subacute-isodense; chronic-hypodense).(4) The subdural hematoma can be differentiated from epidural hematoma by its concave shape over the cortex as opposed to the convex shape of the latter; also, it is less uniform and less dense.(5)

Subdural haemorrhage with a thickness over $10 \mathrm{~mm}$ or with midline shift over $5 \mathrm{~mm}$ poses clear indication for surgical evacuation. If thickness is less than $10 \mathrm{~mm}$ and midline shift is less than $5 \mathrm{~mm}$, surgery should be considered if: there is a GCS decrease since admission with 2 points or more; patient presents unequal pupils; the intracranial pressure is over $20 \mathrm{~mm} \mathrm{Hg.(6,7)}$ Subdural hematoma represents a medical emergency and it should be evacuated as soon as possible in case the surgical criteria are met.(8)

There is another important factor that should be considered in the surgical decision: the anticoagulation therapy.
Patients with good neurologic status receiving anticoagulants must have the anticoagulation reversed before surgery.(9)

Evacuation of blood collection reduces subdural pressure and produce clinical improvement. Residual subdural fluid after surgery is common, but the clinical improvement is not affected by this. It is not recommended to treat persistent fluid evident on post-op CT.(10,11)

\section{CASE REPORT}

We present a case of 74-year old patient, female, known for diabetes, high blood pressure, obesity, chronic heart failure, receiving anticoagulant treatment, bronchial asthma who has presented in the Emergency Department of Sibiu after a traumatic brain injury with headache.

Neurological examination revealed an orientated, conscious, cooperative patient, with no anisocoria, no muscle weakness and no vomiting, GCS E4V5M6.

CT scan showed an acute subdural hematoma with 9 $\mathrm{mm}$ thickness, $4 \mathrm{~mm}$ midline shift, located over the right hemisphere (figure no. 1). No fracture was identified on the skull.

Figure no. 1. Axial CT: Acute subdural hematoma

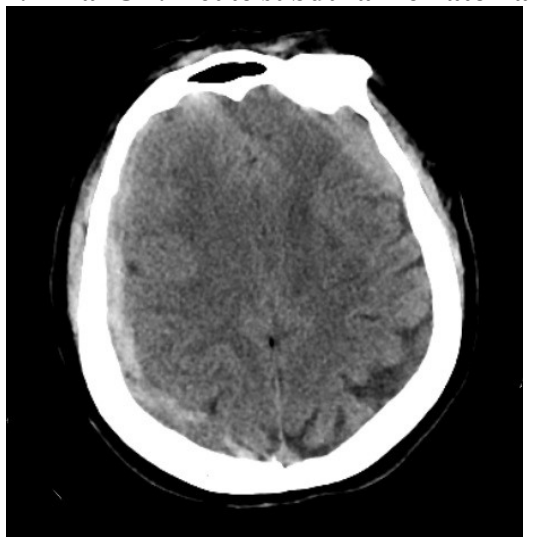

${ }^{2}$ Corresponding author: Alexandru Babeu, Str. Aurel Decei, Nr. 1, Sibiu, România, E-mail: alexandrubabeu@yahoo.com, Phone: +40722386955 Article received on 20.03.2019 and accepted for publication on 28.05.2020 


\section{CLINICAL ASPECTS}

The decision was not to perform surgery, as the criteria were not met. After 4 days another CT scan was performed revealing a decrease of thickness to $7 \mathrm{~mm}$ (figure no. 2).

Considering the clinical improvement and the second CT scan findings, the patient was discharged home, orientated, cooperative, without headache.

\section{Figure no. 2. Axial CT: Subdural hematoma after 4 days}

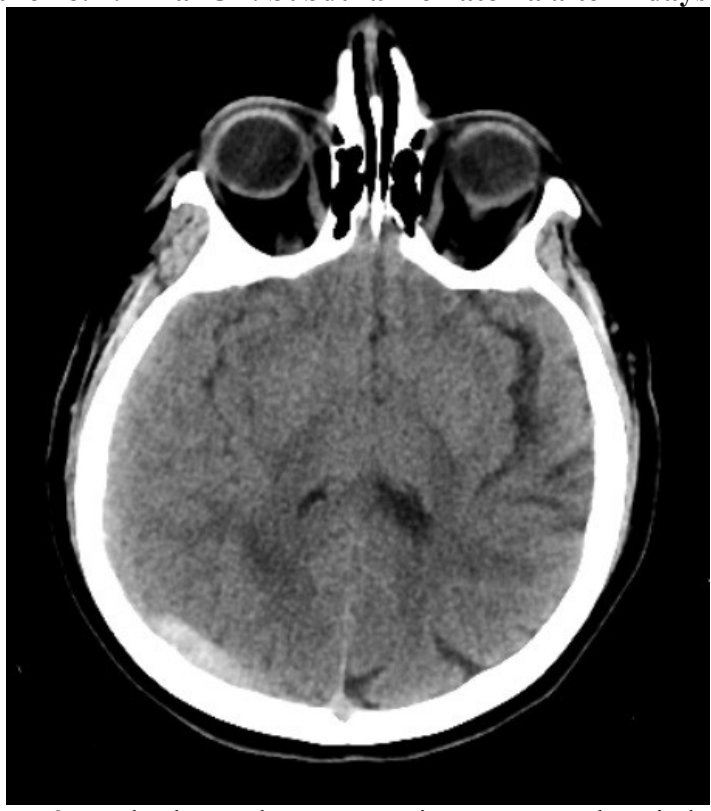

2 weeks later, the same patient came to hospital with headache, paraesthesia on left upper limb, Romberg positive, no signs of meningeal irritation.

The CT scan revealed a right sided fronto-parietal recurrent chronic subdural hematoma with mass effect (figure no. 3).

Figure no. 3. Axial CT: Chronic subdural hematoma preoperatively

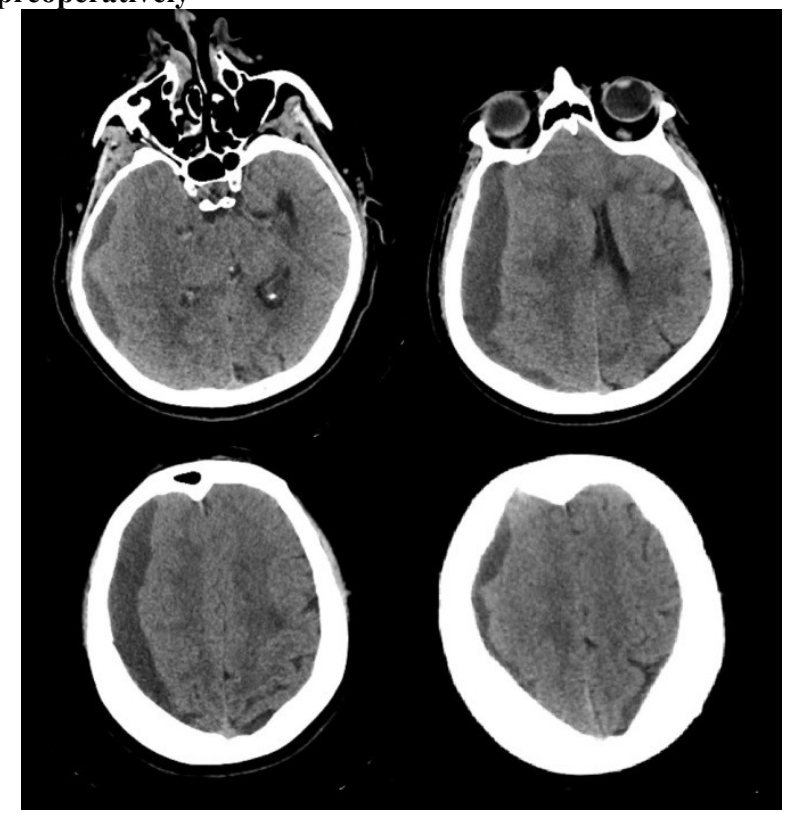

The final decision was to perform surgery for evacuation of hematoma.

Surgical technique: 1. left parietal scalp incision; 2. single burr hole; 3 . dural incision; 4. evacuation of hematoma and hemostasis; 5 . closure of all anatomical layers.
Postoperative CT scan has revealed the subdural hematoma was partially evacuated (figure no. 4).

Patient had a significant clinical improvement after surgery and she was discharged after 4 days with a GCS of E4V5M6, orientated, with resolved neurological symptoms; the follow-up will include clinical and imagistic reviews.

Figure no. 4. Axial CT: Post-operative chronic subdural hematoma

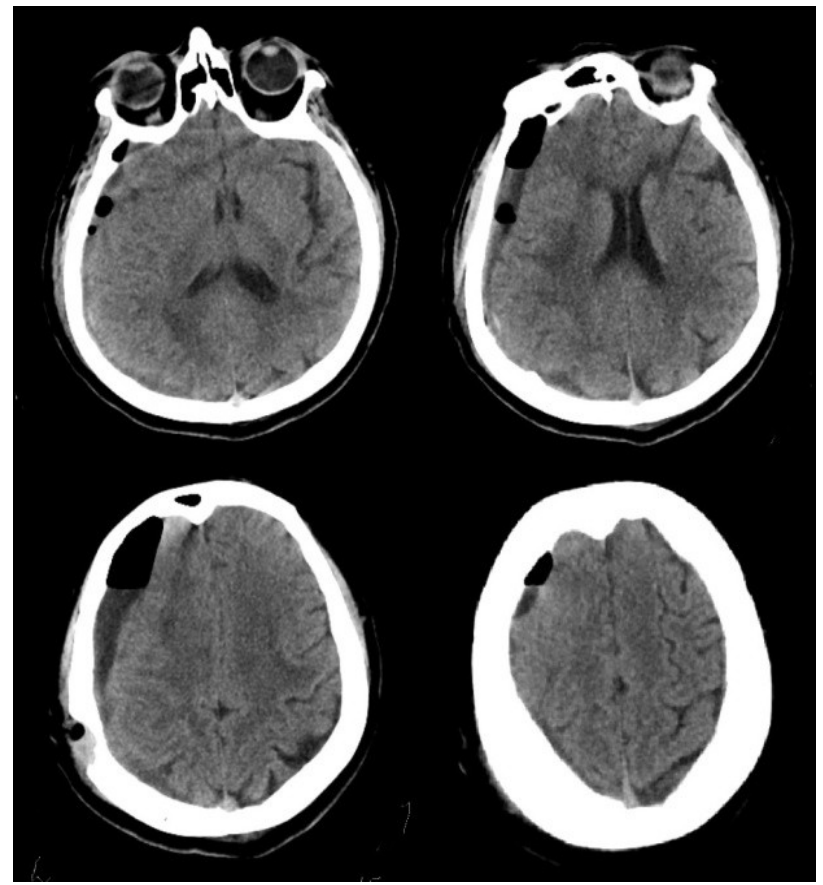

DISCUSSIONS

This case presents an unusual evolution of an acute subdural hematoma in an elderly patient with hypertension (HTA) under anticoagulant therapy. The initial decrease of the hematoma thickness was followed by a considerable increase and mass effect in the next 2 weeks.

The main cause of subdural haemorrhage is head trauma. Acute subdural haemorrhage can be caused by accumulation of blood around parenchymal laceration or by torn of bridging vessel from cerebral acceleration-deceleration during violent head motion. CT scan shows a mass with increased density adjacent to inner table, usually located over convexity, concave over the brain. When surgery treatment is indicated it should be proceed as soon as possible.(2)

Chronic subdural haemorrhage is more often found in the elderly (average 65 years) and is caused by injury in less than $50 \%$ cases, hypertension and anticoagulant therapy being more often the main cause.(2)

In the present case, our patient met both etiological ways (traumatic and non-traumatic) which led to chronic subdural haemorrhage. In the first time, acute subdural haemorrhage was associated with a poor clinical presentation. Symptoms and CT scans highlighted forward a clinical improvement and resorbtion of hematoma.(12)

High blood pressure, anticoagulant therapy and age, were important risk factors who contributed to developing of a massive chronic subdural hematoma in the next 2 weeks.(13)

As a common feature in elderly patients, the symptoms appear delayed and only when the mass effect of the lesion is significant. $(14,15)$

The decision to perform surgery came when mass effect appears on CT (midline shift over $5 \mathrm{~mm}$ in this case). 
The single burr hole technique with irrigation and aspiration was successfully performed for evacuation of blood. There were no surgical complications.

Residual fluid after evacuation of hematoma is common, but clinical improvement does not require complete resolution.(2)

In this case, clinical improvement was observed even if there is residual postoperative hygroma.

\section{CONCLUSIONS}

The main investigation was CT scan.

At least partial evacuation of subdural hematoma may produce clinical improvement.

Acute subdural hematoma must be monitored and assessed periodically even in conservative treatment management.

\section{REFERENCES}

1. Săceleanu V, Pereanu, M. Neurochirurgie clinică. Sibiu: Editura Universității „Lucian Blaga” din Sibiu; 2014.

2. Greenberg MS. Handbook of Neurosurgery. Ninth Edition; 2020.

3. Marcolini E, Hine J. Approach to the Diagnosis and Management of Subarachnoid Hemorrhage. West J Emerg Med; 2019.

4. Săceleanu V. Cerebral Vascular Malformation - an incidental discovery after a traumatic brain injury. Acta Medica Transilvanica. 2017;22(3):31-33.

5. Khurram A, Kleinig T, Leyden J. Clinical associations and causes of convexity subarachnoid hemorrhage. Stroke. 2014;45:1151-1153.

6. Ciurea A. Tratat de Neurochirurgie. București: Editura Medicală; 2011

7. Săceleanu V. Teză de doctorat. Opţiuni terapeutice şi strategice de reinserţie socială în hemoragia intracerebrală primară supratentorială; 2012.

8. Hinojosa AQ, et al. Schmidek \& Sweet Operative Neurosurgical Tehniques. Indications, Methods and Results. Sixth Edition; 2012.

9. Coutinho JM, Stam J. How to treat cerebral venous and sinus thrombosis. J Thromb Haemost. 2010;8:877-883.

10. Shimizu Y, Park C, Tokuda K. Gradation density hematoma is a predictor of chronic subdural hematoma recurrence associated with inflammation of the outer membrane; 2020.

11. Liu LX, Cao XD, Ren YM, Zhou LX, Yang CH. Risk Factors for Recurrence of Chronic Subdural Hematoma: A Single Center Experience; 2019.

12. Kulesza B, Litak J, Mazurek M, Nogalski A. Initial Factors Affecting 6-month Outcome of Patients Undergoing Surgery for Acute Post traumatic Subdural and Epidural Hematoma; 2020.

13. Heydari F, Golban M, Majidinejad S. Traumatic Brain Injury in Older Adults Presenting to the Emergency Department: Epidemiology, Outcomes and Risk Factors Predicting the Prognosis; 2019.

14. Iki Y, Morofuji Y, Kanamoto T, Horie N, Izumo T, Anda T, Matsuo T. Traumatic Middle Meningeal Arteriovenous Fistula of Non-fractured Site Detected by Four-dimensional Computed Tomography Angiography: A Case Report; 2020.

15. Christopher M Loftus. Neurosurgical Emergencies. Thieme. Third edition; 2020. 